\title{
QUESTÃO AGRÁRIA E LUTA PELA TERRA E PELA REFORMA AGRÁRIA NO ESTADO DE GOIÁS NO CONTEXTO DAS TRANSFORMAÇÕES TERRITORIAIS
}

\section{AGRARIAN QUESTION AND THE FIGHT FOR LAND IN THE CONTEXT OF TERRITORIAL TRANSFORMATIONS IN GOIÁS STATE}

\author{
Manoel Calaça \\ Universidade Federal de Goiás - Goiânia - Goiás - Brasil \\ manoelcalaca.geo.ufg@mail.com \\ José Novais de Jesus \\ Universidade Estadual de Goiás - Doutorando em Geografia da Universidade Federal de Goiás - Goiânia \\ - Goiás - Brasil \\ novaisdejesus@yahoo.com.br \\ Ronan Eustáquio Borges \\ Universidade Federal de Goiás - Goiânia - Goiás - Brasil \\ ronanborges@ufg.br \begin{abstract}
Goiás - Brasil
rogerio.mauro@ifgoiano.edu.br
\end{abstract} \\ Rogério Antônio Mauro \\ Instituto Federal Goiano - Doutorando em Geografia da Universidade Federal de Goiás - Goiânia -
}

\section{Resumo}

Este artigo analisa a questão agrária e os processos de luta pela terra e pela reforma agrária no estado de Goiás, no contexto da ocupação e das transformações territoriais. Analisamse as fases do processo de ocupação, a formação do território goiano, a invasão e a tomada dos territórios indígenas, visando a formação dos latifúndios e o fortalecimento do poder dos coronéis e "senhores da terra". A partir da decadência da exploração do ouro, principal atividade econômica da época colonial, formaram-se grandes fazendas para a criação de gado e a produção da agricultura de autoconsumo. Nesse contexto, a grilagem de terras devolutas, a expropriação e a marginalização dos trabalhadores e indígenas se tornaram práticas recorrentes por parte dos fazendeiros para expansão de seus domínios. Essas poucas famílias de donos da terra acabaram por se constituir em nova classe de coronéis no campo, que, articuladas a instâncias do poder federal passaram a exercer o controle político das instituições estaduais. Restou à população que vive do trabalho organizar movimentos camponeses e lutar contra os abusos praticados pela classe dominante e pelo acesso à terra como alternativa de sobrevivência e permanência no campo. Importantes lutas foram e continuam sendo realizadas para mudar essa realidade.

Palavras-Chave: Território. Latifúndio. Luta pela Terra. Reforma Agrária. Camponeses. 


\begin{abstract}
This article analyzes the agrarian question and land-related fights in Goiás State, in the context of occupation and territorial transformations. Analyzes the phases of Goiás territory occupation and formation processes the appropriation of indigenous territories, eventually leading to large estates and empowerment of influential people and "masters of the land". After the waning of gold exploration, the main economic activity in colonial times, large farms were created to raise cattle and promote a subsistence agriculture. Since then, land grabbing, the expropriation and exclusion of workers and indigenous people have become common farmers' practices so as to have their land expanded. The few families related to land owners have constituted a new breed of land masters, which have bonds with the Federal government and have gained political control over state institutions. The working population was left to organize peasant movements and fight against abuses performed by the dominant class and for access to the land, as an alternative to survive and remain in the country. Important fights have been and will continue to be implemented to change such an unfair reality.
\end{abstract}

Keywords: Agrarian Question. Territory. Large Estates. Fight for Land. Peasants.

\title{
Introdução
}

Este artigo reflete sobre a questão agrária, a luta pela terra e pela reforma agrária no estado de Goiás, a partir do processo de ocupação e de formação do território goiano, fortemente ancorado no extrativismo mineral e na exploração agropecuária, que produziu ao longo dos anos uma estrutura fundiária concentrada e excludente.

Trata-se de um processo que teve início no período colonial, quando a exploração do ouro constituía a principal atividade econômica de Goiás. A formação de grandes fazendas foi fruto desse processo de ocupação e de invasão dos territórios indígenas e quilombolas, ainda no período colonial.

A constituição da Primeira República proporcionou o fortalecimento de uma elite local que usava seu poder político e econômico em detrimento dos empobrecidos, que continuaram marginalizados e sem receber a devida atenção para melhorar suas condições de vida. As ações políticas voltadas aos interesses dos mais ricos, que dominavam as principais instâncias de poder no estado, favoreceu a formação do latifúndio.

A Lei de Terras de 1850 que substituiu o Estatuto Sesmarial alterou a lógica de acesso à terra, cuja aquisição, a partir de então, passou a ocorrer apenas pela compra. Deste modo, além de impedir que os escravos libertos e demais trabalhadores livres tivessem acesso à terra, consolidou a formação do latifúndio, reconhecendo os domínios 
das sesmarias e das posses como legítimas. Em Goiás a nova legislação resultou nas condições ideias para a grilagem de terras devolutas, base para a formação de grandes fazendas no Estado. Consolida-se assim, a oligarquia agrária no comando do poder político local.

Uma das consequências do domínio da terra por grandes fazendas foi a subordinação dos trabalhadores por meio do regime de parceria, que se constituiu em mecanismo de superexploração do trabalho e contribuiu para a formação de uma estrutura fundiária altamente concentrada, na medida em que excluía os trabalhadores do acesso à propriedade da terra

As consequências para os povos indígenas goianos também foram desastrosas, com muito sofrimento que incluem a dizimação de muitas tribos e a expropriação de seus territórios. Processos semelhantes ocorreu com milhares de camponeses e quilombolas, expulsos de suas terras pelos grandes fazendeiros. Mas, nunca sem resistência, seja por iniciativas isoladas ou em processos mais organizados social e politicamente, a luta pela terra sempre se fazia presente.

Foram as diferentes iniciativas e experiências de luta pela terra que produziram importantes movimentos de camponeses e sem-terra que questionavam e continuaram questionando o poder do latifúndio em Goiás. A luta dos posseiros de Trombas e Formoso $^{1}$ e dos parceiros de Orizona contra o Arrendo nas décadas de 1950-1960², são duas fortes expressões que merecem o devido destaque na história de luta e de conquista da terra em Goiás. Tratam-se de experiências coletivas, combativas e organizadas pelos próprios camponeses.

O fim da ditadura cívico-militar constituída em 1964 fortaleceu a luta pela terra em Goiás. Principalmente, pelas ações e lutas da Comissão Pastoral da Terra (CPT), do Movimento dos Trabalhadores Rurais Sem Terra (MST), dos sindicatos dos trabalhadores rurais (STRs) e da Federação dos Trabalhadores da Agricultura do Estado de Goiás

\footnotetext{
${ }^{1}$ SOUZA, R. D. de. Aspectos do debate historiográfico sobre Trombas e Formoso-GO. II Seminário de pesquisa e pós graduação em História UFG/UCG. Goiânia, UCG, 2009. Disponível em: https://pos.historia.ufg.br/up/113/o/IISPHist09_RenatoDias.pdf

${ }^{2}$ Walderêz Nunes Lorreiro. Aspecto educativo da prática política: A luta do arrendo em Orizona. Dissertação de mestrado. FGV. Rio de Janeiro, 1982. Ver ainda, ESTEVES, Carlos L. da Silva. Nas trincheiras: luta pela terra dos posseiros de Formoso e Trombas (1948-1964) uma resistência ampliada. 2007. Dissertação. Mestrado em História Social/Contemporânea. Niterói, UFF, 2007. 168p.
} 
(FETAEG). Nesta nova fase, a principal tática de luta para pressionar o poder público a implementar reforma agrária passou a ser a ocupação de latifúndios. Mas como toda ação tem sempre uma reação, também se verificou o aumento dos conflitos e da violência no campo contra camponeses, indígenas e quilombolas.

De todo modo, as lutas e ações concretas de diferentes sujeitos e representações, evidenciam a existência e a atualidade de uma questão agrária não resolvida. A categoria questão agrária ganhou evidência no final do século dezenove, a partir da obra de mesmo nome, de Karl Kautsky (1986). A partir de então a expressão passou a ser utilizada com frequência para designar o problema agrário, que consiste, fundamentalmente, na desigualdade do processo de apropriação privada da terra. Foi somente a partir do aprofundamento dos estudos da questão agrária que passou a ganhar vida a principal forma de enfrentar o problema - a luta pela reforma agrária.

Apesar das inúmeras interpretações e modelos possíveis, a grosso modo a reforma agrária pode ser compreendida como um processo de reestruturação fundiária, acompanhada por um conjunto de políticas públicas capazes de promover desenvolvimento econômico, social e cultural.

A luta pela terra antecedeu o debate e a luta pela reforma agrária e de certa forma, se confunde com a luta contra a exploração do trabalho, desde meados do Século XIX. O debate sobre a reforma agrária foi introduzido na pauta dos movimentos sociais a partir ações das ligas camponesas e da discussão sobre o papel da agricultura na economia brasileira na década de 1950. As ações políticas do Partido Comunista Brasileiro (PCB), como a que ocorreu na revolta dos camponeses em Trombas e Formoso no Norte Goiano, já citada, foi muito importante no debate político e acadêmico sobre a reforma agrária. Portanto a luta pela terra é uma luta histórica na sociedade brasileira, que foi encampada na pauta política a partir dos anos de 1950/1960.

A partir de 1960 observou-se um debate maior em torno do tema reforma agrária no cenário político. Nesta época quatro centros de reflexão se destacaram: o Partido Comunista Brasileiro (PCB), setores reformistas da Igreja Católica, a Comissão Econômica para a América Latina e o Caribe (CEPAL) e os economistas conservadores da USP. Nos setores reformistas da Igreja Católica a chamada doutrina social da Igreja teve papel fundamental para trazer o tema reforma agrária à tona. Nos anos seguintes estes setores da Igreja foram de grande valia na organização sindical no campo e defenderam a idéia da legitimação da propriedade fundiária com base no princípio da função social, princípio este que estaria presente também no Estatuto da Terra 
(1964), na Constituição da República (1988) e que viria suplantar a idéia da terra como mera mercadoria vigente desde a Lei de Terras de 1850. (MEDEIROS, sem data, p. 5).

Portanto, pode-se afirmar que a luta pela reforma agrária advém da luta pela terra e ambas ocorrem hoje concomitantemente, como resultado da ação dos movimentos sociais, como no caso do Movimento dos Trabalhadores Rurais Sem Terra (MST), que tem como um de seus principais objetivos a Reforma Agrária Popular.

Partindo desta compreensão, entende-se que para melhor entender a formação da questão agrária, sua atualidade e as lutas por terra e por reforma agrária em Goiás, é necessário discutir a formação do território goiano, com suas interfaces e contradições. Em especial, os processos de espoliação e expulsão de seus territórios a que foram submetidos os indígenas, camponeses e quilombolas, marcado historicamente por conflitos com os coronéis detentores de forte poder político e econômico, originado no controle da posse e da propriedade da terra.

\section{A formação do território goiano e a questão agrária}

Para refletir sobre a formação territorial e o povoamento em Goiás, o ponto de partida são os primeiros habitantes desses territórios, ou seja, as diferentes nações indígenas que aqui habitavam e reproduziam sua existência. De acordo com Barbosa, Teixeira Neto e Gomes (2005, p. 49):

[...] podemos afirmar que o sul da antiga capitania de Goiás era o espaço privilegiado dos Kayapó e dos Goya, o norte era o domínio dos Apinagé, dos Xambioá, dos Xerente, dos Krahó, dos Akroá e dos Xakriabá. Os Karajá se estabeleceram no baixo rio Vermelho e nas margens do Araguaia, e aí vive há mais de mil anos. Os Xavantes e os Canoeiros, menos propensos à vida gregária que outras nações indígenas, vaguearam por muito tempo ao longo do vale do rio Tocantins, até praticamente desaparecerem do território goianotocantinense exauridos pelas guerras e batalhas travadas contra os colonos invasores. Numa relação desigual de forças, o índio não teve como impedir que, sobre o seu território, se instalasse outro - o território institucional da capitania de Goiás.

Desse modo, os povos indígenas que habitavam o território goiano foram os primeiros a sofrer perseguição com a institucionalização administrativa da Capitania de Goiás. Em função das jazidas de ouro, Goiás se tornou território atrativo a exploradores, principalmente pelos bandeirantes paulistas, que vinham em busca do precioso metal. 
Segundo Pessoa (1999, p.34):

Depois de incursões de bandeirantes na região, numa perspectiva meramente extrativista, o início da ocupação das terras e do povoamento do estado de Goiás se deu nas primeiras décadas do século XVIII, a partir de duas "frentes colonizadoras": uma pelo Sul - iniciativa dos "bandeirantes paulistas" - e outra pelo Norte, com a entrada de migrantes da Bahia, Pará e Maranhão.

Vê-se, assim, que os fluxos migratórios de outras regiões, como Sudeste, Nordeste e Norte, contribuíram para a expansão da população do estado e para a ocupação econômica de seu território, ainda em processo de formação. Além da mineração, grandes fazendas de criação de gado também foram formadas, e a agricultura de autoconsumo. Nesse contexto, a grilagem de terras devolutas se tornou prática cotidiana entre os migrantes (fazendeiros) que detinham maior poder econômico e influência política.

As primeiras cidades goianas surgiram em função da exploração do ouro, a principal atividade econômica da época. Mas diante da decadência da mineração, no século XVIII, projetou-se a agricultura produtora de alimentos, principalmente para autoconsumo, mas que contribuía para o abastecimento dos povoados, ocasião em que muitos trabalhadores das minas, desempregados, passam a trabalhar nas lavouras. Segundo Palacín (2008, p. 67), "Com a decadência ou desaparecimento do ouro, o governo português, que antes procurava canalizar toda a mão de obra da capitania para as minas, passou, através de suas autoridades, a incentivar e a promover a agricultura em Goiás”.

A crise do ouro despertou o interesse do governo português pela agricultura e, assim, parte da mão de obra empregada nas minas foi deslocada para as práticas agrícolas em Goiás. Esse processo de transição da atividade mineradora para a agropastoril foi um marco importante para a análise da reorganização política e a formação da nova base econômica no território goiano.

Segundo Palacin (2008, p.142), "Em todo o estado, continuava dominando a grande propriedade rural, o latifúndio. Isto era uma decorrência ainda do sistema de sesmarias provenientes do tempo colonial e continuado durante o Império". Apesar das dificuldades enfrentadas para produzir e comercializar a produção, devido à carência de infraestrutura e de mercado consumidor, a consolidação do latifúndio foi configurando uma estrutura de propriedade da terra altamente concentrada e excludente, constituindo- 
se uma sociedade agrária formada por pecuaristas, agregados e parceiros, que tinha na produção para o consumo e na criação de gado a base da atividade econômica.

O isolamento geográfico e a falta de meios de transporte e comunicação dificultam o desenvolvimento de práticas mercantis até o início deste século [Século XX]. A pecuária foi a exceção: a produção bovina manteve-se organizada como atividade de mercado e o gado de corte era exportado para os mercados do Centro-Sul e Norte-Nordeste. O comércio do gado garantia certa rentabilidade ao setor agrário e à arrecadação fiscal do erário público estadual. Além disso, o criatório foi a principal atividade econômica responsável pela ocupação efetiva dos sertões em Goiás. (BORGES, 2000, p.94).

Outro aspecto importante a ser considerado se relaciona às disputas políticas, que sofreram influência com o processo de Independência do Brasil de Portugal, contribuindo significativamente para reorganizar as forças políticas locais, a partir da Proclamação da República.

A diretoria do Clube Republicano aclamou Guimarães Natal como presidente do Estado de Goiás. Ele, porém, não aceitou tamanhas responsabilidades, sugerindo a criação de uma junta governativa, assim constituída: Guimarães Natal (presidente), José Joaquim de Souza e major Eugênio Augusto de Melo. (PALACÍN, 2008, p.125-6).

Pensava-se que, com essa junta governista, Goiás poderia se desenvolver, tanto do ponto de vista econômico, como social. Mas esses rearranjos políticos fizeram com que as preocupações se voltassem para as questões administravas e políticas. Sobre a Proclamação da República e seus efeitos em Goiás, Palacin (2008, p. 126) afirma que:

[...] prenderam-se a questões administrativas e políticas. Os fatores sócioeconômicos e culturais não sofreram abalos: o liberto continuou flutuante, caminhando para o marginalismo social; as elites dominantes continuaram as mesmas; não ocorreu a imigração européia; os latifúndios improdutivos, áreas imensas, continuaram por povoar e explorar; a decadência econômica permaneceu sem que se pensasse em modificar a estrutura de produção; a pecuária e a agricultura continuaram deficitárias; a educação, em estado embrionário; o povo continuou esquecido em suas necessidades, mas usado pelos hábeis políticos, que baixavam decretos em seu nome. (PALACIN, 2008, p. 126).

Deste modo, a Primeira República fortaleceu um grupo político local que exercia seu poder declaradamente em prol das elites e em detrimento dos pobres e marginalizados. Esse processo, de um lado favoreceu a formação e consolidação dos latifúndios e de outro o empobrecimento da maioria da população do campo e da cidade, na medida em que não alterou a estrutura produtiva e o acesso à terra. 
A experiência com o regime republicano projetou famílias que se constituíram como donas do poder local. Mas também trouxe para o cenário político as disputas políticas locais. Como diz Palacín (2008, p.126), "Os primeiros anos de Goiás República estão cobertos de lutas pelo poder político. São elas em parte reflexos da conjuntura nacional".

A política nacional provocou reorganização do poder na esfera estadual, fortalecendo grupos familiares como "os Bulhões, Jardim e Caiado". (PALACIN, 2008), que também passaram a exercer influência na esfera nacional. Essa concentração de poder se deu a partir de acordos firmados segundo seus interesses. Vale afirmar que esses grupos políticos se fortalecem como elite política por várias décadas e que atualmente ainda se mantém no cenário político estadual e nacional.

Nesse sentido, as mudanças que ocorreram na política, na economia e na sociedade goiana nos permitem analisar as fases do processo da formação do território goiano, as ocupações e a tomada dos territórios indígenas, a formação do latifúndio improdutivo excludente e o fortalecimento do poder dos coronéis.

Em relação à questão da terra, a garantia para esses grupos veio com a aprovação da Lei de Terras de 1850 - que garantiu a expansão fundiária e poder desses grupos para expandir seus domínios, já que dispunham dos recursos financeiros necessários.

\footnotetext{
Do ponto de vista da formação fundiária, a Lei de Terra não criou nada de novo. Ela apenas ratificou e legitimou o latifúndio, definitivamente estabelecido no período das ocupações. Mas do ponto de vista econômico, sim. Até a Sesmaria, a terra conferia prestígio social, do qual o poder econômico. A partir da Lei de Terras, a terra passou a representar poder econômico do qual deriva prestígio social. (PESSOA, 1999, p. 44).
}

Desse modo, os escravos que haviam recebido a sua "liberdade" foram marginalizados e excluídos desse processo, pois a liberdade anunciada era falsa - porque não foi lhes garantido o direito ao acesso à terra. Com isto, formou-se um exército de reserva de mão obra de ex-escravos que, sem nenhuma perspectiva, passou a vender a sua força de trabalho para os latifundiários e se submeter à exploração e à subordinação dos seus novos patrões.

Vale observar que essa Lei trouxe apenas a libertação dos latifundiários em relação à coroa portuguesa, mantendo-os senhores de terras como antes, assegurando as condições para seguir oprimindo os trabalhadores sem-terra escravizados, que foram 
excluídos da possibilidade de acesso à terra. Em suma, a Lei de Terras contribuiu para fortalecer a expansão e a consolidação do latifúndio e formou nova classe dos "senhores de terra".

O projeto político que colocou Goiás no cenário da economia nacional iniciou com a Marcha para o Oeste e se consolidou com a construção de Brasília, criando as bases para a nova dinâmica econômica no interior do país, ou seja, no Planalto Central.

\begin{abstract}
O pacto agro-exportador das primeiras décadas do presente século, Getúlio Vargas o substituiu pelo pacto populista, compreendido assim pela história por contemplar interesses tão díspares como os da burguesia agrária remanescente, da burguesia urbano-industrial e do operariado urbano emergente. A bandeira que tornou isso possível foi a industrialização (substituição de importações). Nesse contexto se explicam, por exemplo, a ambigüidade da posição brasileira frente à Segunda guerra Mundial, a posterior campanha em torno da questão do petróleo e o próprio fim trágico de Getúlio. Mas é nesse contexto que se explica também a interiorização do Estado - no sentido litoral- interior a Marcha para o Oeste. (PESSOA (1999, p.46).
\end{abstract}

Com forte campanha publicitária por parte do governo, diferentes atores econômicos aderiram à campanha da "Marcha para o Oeste" pois compreendiam que esse projeto promoveria grandes descobertas das potencialidades existentes no interior do país. Dentre as iniciativas a serem tomadas, estava a construção de ferrovias e rodovias, de modo a criar infraestrutura básica e isso culminaria com a entrada de capitais e, assim, o Centro-Oeste se inseria na lógica desenvolvimentista de um Estado moderno.

A Marcha para o Oeste apontava importantes possibilidades agrícolas no estado de Goiás. Para viabilizá-las, foi criada infraestrutura rodoviária e a Colônia Agrícola de Goiás (CANG), onde se localizam atualmente os municípios de Ceres e Rialma, na região central do estado.

\footnotetext{
A primeira metade da década de 1950 pode ser caracterizada pela grande corrida em busca da titulação de terras no Norte de Goiás e também na Zona do Alto Tocantins (região em que localizava Trombas), evento relacionado ao impacto que teve a construção da Colônia Agrícola e das rodovias numa região marcada pela grande quantidade de "terras livres". (MAIA, 2008, p.132).
}

Dentro do contexto desenvolvimentista, Goiás detém as condições de solo e de topografia favoráveis à produção de alimentos. Havia, entretanto, a necessidade de investimentos em infraestrutura visando o escoamento da produção da CANG. A criação da CANG despertou também a preocupação com a titulação das terras, principalmente no 
Norte de Goiás, pois a luta de Trombas e Formoso fez com que os coronéis temessem que as terras fossem ocupadas por camponeses.

[...] com a Marcha para o Oeste, Goiás foi incorporado ao processo produtivo nacional como fornecedor de gêneros alimentícios e matérias-primas e, principalmente, como absorvedor dos excedentes populacionais de outras regiões do país. E (a política estadual, confiada por Getúlio ao interventor Pedro Ludovico Teixeira "um filho da revolução de 1930"), criou as condições necessárias para a implementação da ocupação do estado. (PESSOA, 1999, p. 47).

O objetivo da Marcha para o Oeste era ocupar os espaços de "vazios demográficos" no interior do país, em nome da segurança nacional. Esse projeto audacioso criava as bases mínimas e as condições necessárias para viabilizar a expansão da fronteira agrícola, mediante a injeção do capital agrário na Região Centro-Oeste e na Amazônia. Isso se consolidou mais tarde com a modernização conservadora da agricultura, com a implementação do pacote tecnológico da Revolução Verde, que teve a sua expansão no pós-guerra.

\begin{abstract}
A conquista da terra por atividades econômicas modernas, por meio dos chamados ciclos da economia, mostra a escolha, em cada momento, de áreas diversas de implementação. De início é, sobretudo o litoral que é ocupado, seguindo-se vagas de expansão, as diversas frentes pioneiras. Mas somente na segunda metade do século XX é que o território brasileiro pode ser considerado completamente apropriado, ainda que subsistam descontinuidades principalmente na região amazônica. (SANTOS e SILVEIRA, 2005, p. 249).
\end{abstract}

A partir dessas contradições inerentes a esse processo, surgiram no Brasil os partidos de esquerda, as lutas camponesas e dos trabalhadores operários. Essas mudanças surgiram com as mobilizações populares que exigiam mudanças nas estruturas econômica, política, educacional e social. A luta pela reforma agrária se tornou bandeira de reivindicação dos movimentos camponeses, em escala nacional.

A "modernização" trouxe muitas consequências, tanto para o campo como para a cidade, tais como a exclusão dos camponeses pobres do processo de modernização, o aumento da concentração da terra; a intensificação das monoculturas; o aumento dos conflitos e da violência no campo; uso intensivo de venenos e fertilizantes na agricultura que; além de problemas ambientais e para a saúde humana.

É importante salientar que, no planalto central, a agricultura moderna se desenvolveu e tinha como objetivo atender as demandas do mercado externo. 
As inovações tecnológicas produzidas a partir das pesquisas realizadas pelo Empresa Brasileira de Pesquisas Agropecuárias (EMBRAPA) transformaram os solos do Cerrado, até então improdutivos, em solos altamente produtivos e rentáveis do ponto vista econômico, mediante a adição de insumos e o desenvolvimento de variedades de sementes adaptadas às condições edafoclimáticas e pedológicas do Cerrado. O preço irrisório das terras favoreceu aos que detinham algum capital a formar grandes latifúndios que, na sua maioria, continuam improdutivos ou servindo apenas para fins especulativos. Ainda de acordo com Mendonça (2004, p.147): vários fatores contribuíram para o processo de expansão da modernização da agricultura no território goiano.

A agricultura moderna se desenvolveu no Cerrado goiano a partir de vários fatores que, associados, possibilitaram êxito aos novos investidores. A presença dos chapadões com topografia plana, a disponibilidade de terras latifúndios improdutivos e terras devolutas, a presenças de grandes reservas de água para projetos de irrigação e, principalmente, as políticas creditícias e fiscais subsidiadas pelo Estado foram primordiais para o (re) ordenamento territorial imposto pelas empresas rurais. Soma-se a esses fatores o próprio movimento do capital que carecia de áreas para promover investimentos, como, por exemplo, a indústria de insumos, de fertilizantes e de maquinários que necessitava ampliar mercados.

O fato é que a agricultura moderna se consolidou com a ampliação da base técnica de produção, contribuindo significativamente na transformação de espaços improdutivos em terras produtivas, em função do uso da ciência e da técnica colocadas a serviço do capital.

O Estado ocupa posição de destaque, neste contexto, por ter transformado o Cerrado brasileiro em celeiro da produção nacional. Este território vem assumindo a marca do processo moderno de produção agrícola brasileira. Assim, o paralelo entre Estado e território, tendo a agricultura do Cerrado, como caminho, orienta a proposta metodológica de discussão do tema e delineia a teia de fundamentos teóricos que sustentam o processo de modernização territorial do Cerrado. E para apreender o papel da agricultura, neste processo, é tomado como exemplo o Programa de Cooperação NipoBrasileira para o Desenvolvimento dos Cerrados, PRODECER, considerado o maior programa de intervenção público/privada sobre o Cerrado e principal dinamizador territorial. (INOCÊNCIO; CALAÇA, 2010, p. 274). ${ }^{3}$

As ações oriundas desses programas modificaram a paisagem do Cerrado, ao substituir a vegetação nativa das chapadas por lavouras de grãos e cana-de-açúcar,

\footnotetext{
${ }^{3}$ Sobre o PRODECER ver Maria Erlan Inocêncio, O PRODECER E AS TRAMAS DO PODER NA TERRITORIALIZAÇÃO DO CAPITAL NO CERRADO. 2010. $271 \mathrm{f}$. (Tese de doutorado). Instituto de Estudos Sócio Ambientais/Universidade Federal de Goiás(UFG). Goiânia, 2010.
} 
impondo nova lógica produtiva do espaço agrário, que faz uso de forte aparato tecnológico que mudou a forma de produzir no Cerrado. Vale lembrar que o avanço desse modelo agrícola predatório no Cerrado culminou com a desarticulação das práticas camponesas, antagônicas às práticas da agricultura empresarial, que é subordinada às empresas do agronegócio. O Gráfico 01 mostra o domínio da agricultura empresarial capitalista sobre a agricultura familiar, que inclui camponeses, quilombolas, indígenas, considerando a produção de soja e arroz no estado de Goiás e os dados referentes à produção agropecuária em 2017.

Gráfico 01: Estado de Goiás - Quantidade (ton) produzida de arroz e de soja pela agricultura familiar e não familiar -2017
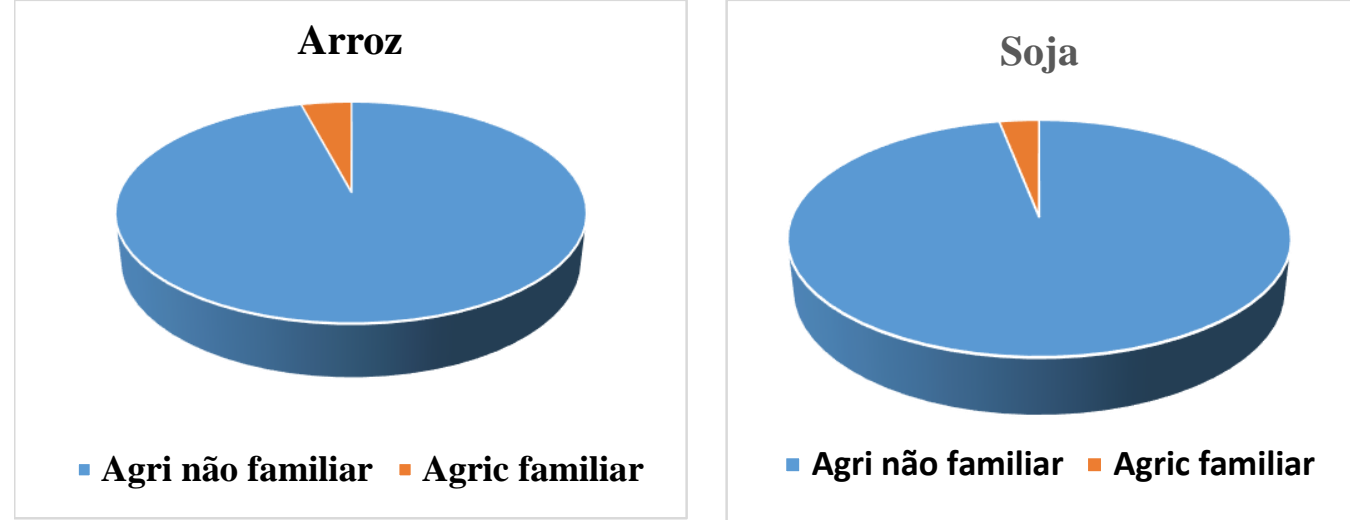

Fonte: IBGE - CENSO AGROPECUÁRIO - 2017.

A concentração da terra se apresenta como um problema crônico e histórico no estado e tem como uma das consequências mais visíveis as desigualdades sociais, tanto no espaço rural quanto no espaço urbano. Como resposta a essas desigualdades, surgiram movimentos sociais de resistência e luta pela terra, pela reforma agrária e permanência no campo. Por isso é fundamental discutir essa temática para compreender a questão agrária no estado de Goiás.

O Gráfico 02 apresenta um retrato dessa situação. Apesar dos pequenos imóveis constituírem a maioria absoluta das propriedades é pequena sua participação nas terras. Ao passo que os grandes imóveis, em especial, aqueles com tamanho superior a 1.000 hectares, apesar de seu reduzido número, detinham a maioria absoluta das terras. 
Gráfico 02: Estado de Goiás - Número e área (ha) dos imóveis por classes de área 2018

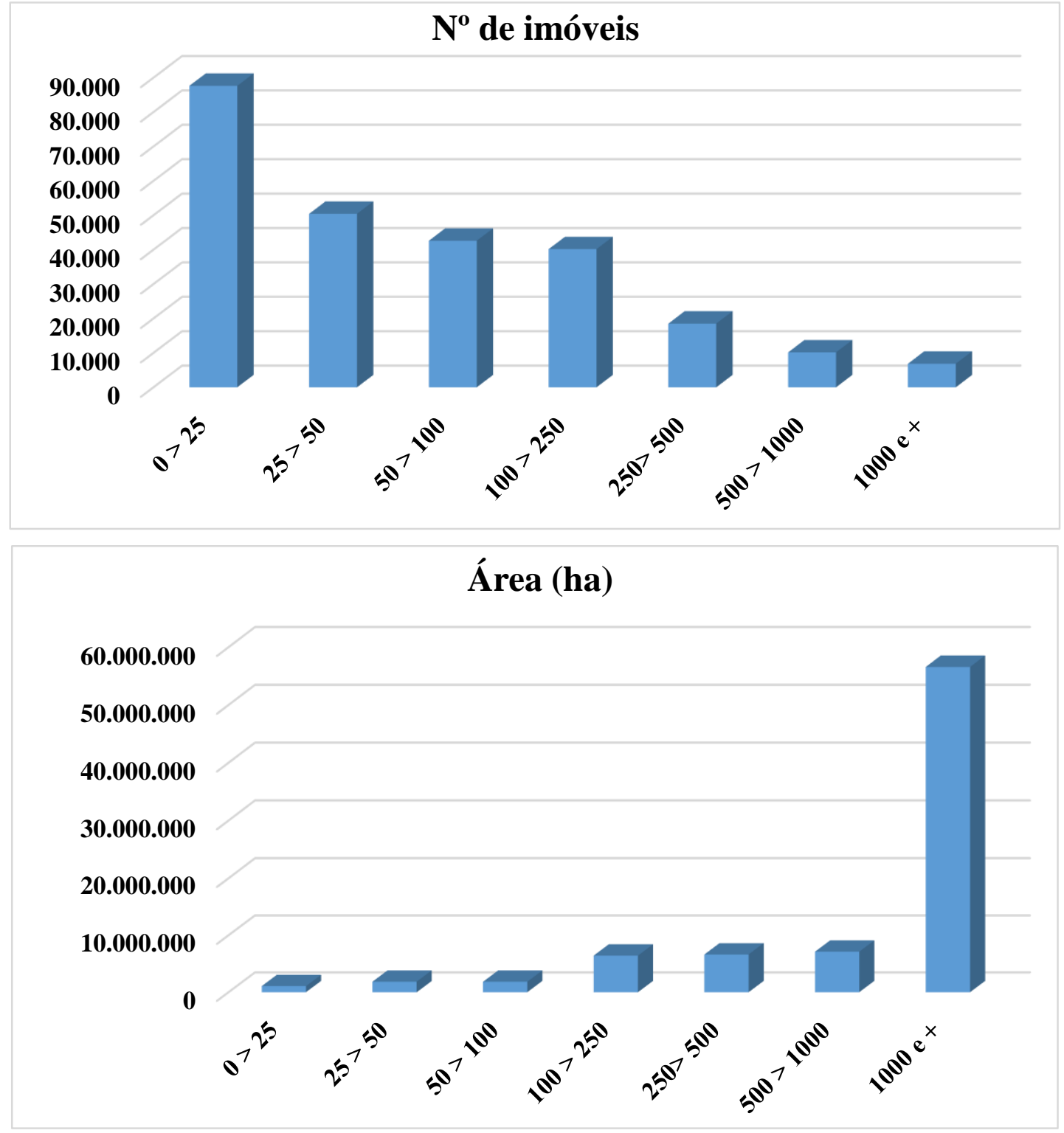

Fonte: INCRA- 2020.

\section{A luta pela terra e pela reforma agrária em Goiás}

O Brasil caracteriza-se por elevados índices de concentração da terra, com os maiores latifúndios que a história já registrou. As lutas camponesas no campo brasileiro se transformou em marco histórico de resistência e confronto com o poder opressor e a violência dos latifundiários. A resistência se efetiva na luta pela terra e pela reforma agrária, pela permanência no campo, por justiça e em defesa da vida. A distribuição 
desigual das terras no Brasil e a aplicação de modelo agrícola com baixo u de trabalho humano foram responsáveis pela exclusão e espoliação dos trabalhadores camponeses e sem-terra, que, sem perspectivas de reprodução da vida no campo, iniciaram processo de mobilização e de enfrentamentos deflagrados em várias regiões do País.

\begin{abstract}
As lutas camponesas não são recentes no Brasil. Basta lembrar Canudos, (1896-1897), Contestado (1912-1916), Trombas e Formoso (1950-1957), entre outras, para perceber que os conflitos no espaço agrário brasileiro têm um processo histórico, político e social antigo, complexo e merecem ser estudados. (MATOS, CUNHA E ALENCAR, 2013, p. 68).
\end{abstract}

As primeiras experiências contestadoras contrárias ao regime fundiário, citadas pelos autores supramencionados, onde os pobres excluídos reivindicavam a posse da terra e a reforma agrária por meio da luta organizada, datam do final do século XIX. Conforme Matos, Cunha e Alencar (2013, p.68), "O campesinato confrontou-se muitas vezes com fazendeiros, latifundiários, grileiros, empresários e o Estado. No entanto, os registros dessas resistências são praticamente ignorados pela história oficial”. Essas lutas permanecem no final da segunda década do século XXI, uma característica da fronteira agrícola, no Cerrado e fora dele.

A exploração da terra em Goiás se diferencia no espaço e no tempo, de acordo com o potencial econômico e a localização de cada região. O Sul Goiano é uma região que recebeu grandes volumes de investimentos em função da proximidade com São Paulo e Triângulo Mineiro, e por apresentar relevo plano, solos profundos e com fertilidade ${ }^{4}$ para o cultivo de grãos. A partir da década de 1970, foram instaladas obras de infraestrutura rodoviária, energia elétrica, sistema moderno de comunicação e informação e logística necessária para viabilizar as atividades agrícolas e agroindustriais. Enquanto a região Norte não recebeu a atenção devida, o que resultou no desenvolvimento desigual do estado, cumprindo sua função na divisão territorial do trabalho e da produção. Esse processo foi antecedido pelas ações de Vargas, que criou as condições objetivas, com a Marcha para o Oeste e os governos JK e da ditadura civil-militar de 1964, que instalou as infraestruturas para o avanço da fronteira agrícola para a Região Centro-Oeste.

\footnotetext{
${ }^{4}$ A fertilidade potencial do solo do Cerrado foi viabilizada pela correção do $\mathrm{Ph}$ do solo, tornando-o adequado para o plantio de grãs e outros produtos agrícolas, como cana-de-açúcar, trigo, seringueira dentre outras. Esse processo só foi possível com a criação da EMBRAPA, que desenvolveu pesquisas que possibilitou o uso "racional" do Cerrado.
} 
A ocupação das matas do Médio Norte Goiano no final da década de 1940 e início da década de 1950 não foi somente mais um simples avanço da fronteira agrícola de Goiás. Este novo deslocamento carregava uma singularidade que iria marcar definitivamente os conflitos agrários em toda esta região: a possibilidade do acesso a um pedaço de terra pelo pequeno produtor. $\mathrm{O}$ elemento que dava esta esperança a milhares de meeiros e agregados era o encaminhamento, por parte do Governo Federal, da construção da Colônia Agrícola Nacional de Ceres, a primeira de outras sete que foram construídas no Governo de Getúlio Vargas em diversas regiões de fronteira do Brasil. (MAIA, 2008, p. 35)

Como contradição desse processo, o estado de Goiás foi marcado por importantes lutas dos camponeses e sem-terra, destacando-se a revolta camponesa de Trombas e Formoso e a Luta Contra o Arrendo. De acordo com Carneiro (2014, p. 148). "Após um ano de trabalho, de meados de 1954 a meados de 1955, os posseiros de Formoso e Trombas achavam-se organizados e conscientes de seus direitos e de que somente unindo todas as forças é que sobreviveriam”. A luta contra o latifúndio/latifundiários é também a luta contra o capital.

Os acontecimentos de Trombas e Formoso foram marcados por um processo de modernização capitalista caracterizado pela conflitividade, ou seja, camponeses antagonizando-se a aqueles que queriam consolidar um mercado capitalista de terras. Então, mesmo as formas tradicionais de produção do campesinato e a resistência a aferição de uma determinada renda da terra assumem características que escapam a esfera estrita da produção e assume os imperativos políticos de uma resistência contra a expansão capitalista. (SOUZA, 2009, p. 1)

A expansão da formação de fazendas no Norte Goiano implicou na intensificação dos conflitos em Trombas, pois nessa porção do estado as terras eram devolutas, o que motivou disputas e luta pela terra, além de lutas contra o pagamento do arrendo aos fazendeiros. $\mathrm{O}$ arrendo era a cobrança de renda da terra em produto, pelos fazendeiros, grileiros etc., chegando a 50\% da produção.

Porfírio tinha plena consciência de que os posseiros não eram donos das terras e nem contavam com títulos legais e sua primeira reação não foi a de buscar a legalidade do terreno, tanto é que, apesar de ter chegado à região em 1950, somente em 1952, no auge dos conflitos pela cobrança do arrendo, é que se direcionou até o Estado para confirmar a situação das terras que, como devolutas, só poderiam continuar sob ocupação dos posseiros se estes requeressem a compra. Diante disto, a visita ao Estado não era uma busca simples da legalidade, mas a tentativa de manter a condição das terras como livres e as posses não como parte do patrimônio de uma fazenda de gado. (MAIA, 2008, p. 100) 
Por conta da instalação da Colônia Agrícola de Goiás (CANG), havia por parte dos posseiros a percepção de que o Estado teria interesse que essas terras fossem ocupadas. Criava-se, assim, a expectativa de uso dessas terras para a continuidade da produção camponesa. A busca por titular as terras era uma demanda para garantir a permanência na terra. Segundo Maia (2008, p.137), “a corrida pelos títulos estava relacionada com estas novas condições da terra, assim como o desejo de criadores de gado e comerciantes de verem os camponeses fora das propriedades em disputas".

José Porfírio de Souza foi uma das principais lideranças do movimento camponês e da luta organizada de Trombas e Formoso. Era uma liderança que compreendia o drama camponês e buscava intervir junto às autoridades constituídas para reivindicar os direitos dos camponeses, que na condição de posseiros possuíam apenas a posse precária da terra. Os camponeses sofreram todo tipo de injustiças, humilhação, perseguição de jagunços e da polícia, já que a lei amparava os grileiros.

A experiência de Trombas e Formoso e das lutas contra o pagamento do arrendo se constituíram em importante marco da luta pela terra em Goiás. O Estado Brasileiro foi incapaz de construir, com base nesses acontecimentos históricos, um projeto de reforma agrária capaz de promover a divisão justa das terras e pôr fim à violência contra o camponês. A ação do capital e a mediação do Estado oligárquico passa a advogar em prol dos fazendeiros e grileiros que adquirem terras para especular, sem preocupação com o cumprimento da função social da terra.

Borges (2000, p. 132) destaca que, "O estado de Goiás, nesse período, com baixa densidade populacional e uma estrutura fundiária altamente concentrada, caracterizavase historicamente como um espaço territorial onde havia uma população sem-terra numa terra despovoada". As transformações técnicas no campo impuseram a saída de milhões de camponeses do campo brasileiro, principalmente, devido à mecanização do processo produtivo, formando um contingente de reserva de mão-de-obra nas periferias urbanas, especialmente nas capitais e cidades médias.

O capital se expandiu no campo a partir desse processo da industrialização da agricultura, numa aliança dos setores capitalistas nacionais com os agentes econômicos internacionais, para explorar as áreas de terras férteis e criar as bases para a exploração capitalista. 
Para Pessoa (1999, p.88), “A década de 1980 começou com uma decidida luta por resistir nas posses já constituídas”. Trabalhadores rurais organizados passaram a resistir e a enfrentar os fazendeiros e o aparelho repressivo do Estado, na defesa da permanência nas posses. Diversas foram as mobilizações de camponeses que contavam com o apoio da Comissão Pastoral da Terra (CPT) e dos Sindicatos de Trabalhadores Rurais (STR). Esse apoio fortalecia os camponeses que também se sentiam encorajados a ocupar latifúndios improdutivos e levar adiante a luta pela reforma agrária. Apesar das dificuldades do embate com os latifundiários, que contavam com o apoio jurídico, político e institucional do Estado, nas diversas escalas. Além de sua própria força repressora formada por jagunços.

No ano de 1985, foi realizado, em Brasília, o $4^{\circ}$ Congresso Nacional dos Trabalhadores Rurais. Na convocação do referido congresso, a Confederação Nacional dos Trabalhadores na Agricultura (CONTAG) expressava todo o otimismo com a "Nova República" para a luta dos trabalhadores rurais:

Cerca de 4 mil trabalhadores rurais de todo o País estarão presentes nos dias 25 a 30 de maio, em Brasília, no $4^{\circ}$ Congresso Nacional dos Trabalhadores Rurais. Esse Congresso deverá ser o maior Congresso de categoria realizado até hoje no País. A classe trabalhadora rural conta com 2.626 Sindicatos e 9.789 mil associados espalhados pelo Brasil. Todos estes Sindicatos estarão representados no Congresso. A realização desse Congresso no atual momento político, marcado pelo fim do regime autoritário e início da "Nova República", será de fundamental importância para os trabalhadores rurais. (CONTAG-MG, Informativo 02, maio de 1985, PAG. 4)

Durante o evento, em discurso proferido pelo então Presidente José Sarney, foi anunciado o Plano Nacional de Reforma Agrária - (PNRA), lançado em 17 de outubro de 1985, que estabelecia como objetivo geral:

Promover melhor distribuição da terra, mediante modificações no regime de sua posse e uso, adequando-a às exigências de desenvolvimento do País através da eliminação progressiva do latifúndio e do minifúndio, de modo a permitir o incremento da produção e da produtividade, atendendo, em consequência, os princípios de justiça social e o direito de cidadania do trabalhador rural. (BRASIL, 1985, pag. 16).

O PNRA visava a aplicação do Estatuto da Terra, a fim de viabilizar o processo de reforma agrária, assentando 1,4 milhões de famílias, no período do mandato do Governo Sarney. Conforme Morissawa (2001, p. 107) o Plano "beneficiava posseiros, parceiros, arrendatários, assalariados rurais e minifundiários”. Muito além disso, do ponto 
de vista político, o principal fato é que o PNRA acabou trazendo a reforma agrária de volta para a pauta política do país.

Entretanto, se o PNRA trazia esperança aos camponeses, causava incômodo e preocupação de parte dos latifundiários, temerosos em relação às possíveis desapropriações de latifúndios para a efetivação da reforma agrária. Diante desse temor, a reação dos ruralistas foi imediata.

\begin{abstract}
Atuando prioritariamente através das principais entidades de representação patronal, em especial a Confederação Nacional da Agricultura (CNA), Organização das Cooperativas do Brasil (OCB) e a Sociedade Rural Brasileira (SRB), os grandes proprietários de terra se organizaram contra a proposta do Plano Nacional de Reforma Agrária e contra as medidas institucionais implementadas pelo governo Sarney. [...] Atuando prioritariamente nas áreas onde eram mais intensos os conflitos de terra e nas regiões onde predominava a pecuária - em especial o Centro-Oeste e o Sudeste - e organizando-se fora dos canais formais de representação patronal, a UDR agregou, nestas regiões, associações de produtores, sindicatos rurais e inúmeros grupos de resistência ao Plano Nacional de Reforma Agrária e às lutas por terra. As primeiras metas da UDR foram no sentido de impedir as medidas de desapropriação, levando ao enfrentamento direto com os trabalhadores rurais nas regiões de conflito e à desqualificação das instituições favoráveis à reforma agrária, em especial a Igreja "progressista". Além disso preparou-se para um conflito armado no campo e incentivou a violência contra os trabalhadores rurais. (BRUNO, [1990?], não paginada).
\end{abstract}

Apesar dos objetivos e das metas estabelecidas, o PNRA não saiu do papel, mesmo contando com dispositivos legais e constitucionais que ofereciam condições para implementá-lo. Esse contexto de ebulição política, acrescido da intensificação do processo migratório do campo para a cidade, criou as condições para o surgimento de outros movimentos sociais de luta pela terra no campo e um ambiente adequado para a formação de novos militantes na demanda por terra e pela reforma agrária.

Em Goiás, o principal movimento de luta pela terra passou a ser o MST, que, segundo Morissawa (2001, p.190), “[...] formou, então, um grupo de famílias para realizar sua primeira ocupação. A área escolhida foi à fazenda Mosquito, terra grilada no Município de Goiás". A ocupação ocorreu em maio de 1985. Vale ressaltar, que os latifúndios ocupados por sem-terra, na sua maioria, foram terras griladas e improdutivas.

Na região do município de Goiás, a Fazenda Mamoneiras, município de Fazenda Nova, foi uma resistência de projeções que se arrastou por toda a primeira metade da década de 1980. Cerca de quarenta posseiros, alguns residindo lá desde a década de 1940, conquistaram a terra (pela força e depois 
na justiça), apesar da grilagem de Wellington Seabra Guimarães, Eduardo Bastos da Cunha e Albatênio Caiado de Goddoy. O decreto de desapropriação, segundo dados do INCRA, saiu em 29 de janeiro de 1987, sob n. ${ }^{\circ} 93.986$. (PESSOA, 1999. p.89).

A ocupação dessas duas fazendas renovou nos camponeses as expectativas de conquistar a terra. Ambas foram desapropriadas porque a justiça reconheceu o direito dos acampados ao acesso à terra. A formação de assentamentos rurais tornou-se a realização concreta de sonhos dos camponeses ao conquistar a sua parcela de terra, por meio das ocupações e da pressão popular.

\begin{abstract}
Continuando em seu intuito de frear a reforma agrária, a UDR financiou a campanha de candidatos de partidos conservadores, como o PPB, O PFL e o PTB, à Câmara e ao Senado, para fazer parte do Congresso Nacional Constituinte de 1987 - 1988. Foi assim que ela conseguiu impor emendas na Constituição que fizeram o Estatuto da Terra andar para trás. A principal delas foi com relação à desapropriação de terras. Antes, pela lei, qualquer latifúndio podia estar sujeito à desapropriação. Eles criaram e conseguiram aprovar a categoria "latifúndio improdutivo" para burocratizar, questionar e impedir os avanços da reforma agrária. Isso porque o conceito de "improdutivo" é amplo e complexo, dando margem a que os latifundiários recorram e impeçam a desapropriação. (MORISSAWA, 2001, p.108).
\end{abstract}

Mesmo com todo esse movimento contrário de parte dos ruralistas, a nova Constituição, promulgada em 1988, fixou novos conceitos para definir e incorporar três regimes fundiários: a) terras destinadas à produção agropecuária subordinadas ao princípio da Função Social da Propriedade (Artigo 186); b) criação dos regimes de terras étnicas (indígenas Artigo 231 e quilombolas, ADCT, Artigo 8º); e o regime das unidades de conservação ambiental (Artigo 226).

O Artigo 186 da Constituição Federal de 1988 estabelece que:

\begin{abstract}
A função social da propriedade é cumprida quando a propriedade rural atende simultaneamente, segundo critérios e graus de exigência estabelecidos em lei, aos seguintes requisitos: I - Aproveitamento adequado; II - Utilização adequada dos recursos naturais e preservação do meio ambiente; III Observância das disposições que regulam as relações de trabalho; IV Exploração que favoreça o bem-estar dos proprietários e dos trabalhadores. (BRASIL, 1988, 103).
\end{abstract}

Apesar do avanço legal, a correlação de forças não permitiu a expansão da desapropriação dos imóveis rurais que não cumpriam a função social para a fixação de assentamentos rurais. Aliás, esse preceito constitucional fundamenta as ações dos movimentos sociais a questionar quando os latifúndios não cumprem com a função social 
da terra, justificando a necessidade das lutas, em especial, das ocupações de terras. Sobretudo, quando falta iniciativa do Estado e da Justiça em promover as desapropriações e assentar os trabalhadores sem-terra.

Cabe observar que a maioria dos assentamentos rurais tem sido fruto das ocupações e da pressão popular, como uma espécie de mecanismo para solução de conflitos e tensões sociais de parte do Estado. Na prática os assentamentos não constituem um projeto de desenvolvimento econômico e social como ocorreu em outros países, no âmbito das chamadas reformas agrárias clássicas.

Apesar dos avanços constitucionais, contraditoriamente, os conflitos e a violência no campo contra camponeses, indígenas e quilombolas aumentaram na "Nova República”. Sobretudo, porque os latifundiários declararam guerra contra a reforma agrária e contra os movimentos sociais. A mobilização ruralista foi aumentando sua força política, principalmente no Congresso Nacional, propondo emendas constitucionais e criando empecilhos jurídicos que, ao longo do tempo, foram dificultando os avanços da reforma agrária, mantendo intocável a maior parte dos latifúndios.

A década de 1990 foi marcada pela instituição das políticas neoliberais no Brasil e pela contra reforma agrária induzida pelas políticas do Banco Mundial, com destaque para programas como Banco da Terra, Cédula da Terra e outros. A articulação ruralista para barrar o avanço da reforma agrária continuou criando tensões e os conflitos no campo foram se agravando. As velhas táticas das oligarquias agrárias como de armar jagunços e pistoleiros para praticar violência contra lideranças sociais e religiosas que lutam pela democratização do acesso à terra continuaram sendo utilizadas.

A UDR firma-se como um movimento dos latifundiários contra a implantação do Plano de Reforma Agrária, já quando fora proposto no Congresso da Contag, além de caracterizar como uma força que usava de métodos violentos para conter as manifestações dos movimentos sociais que reivindicavam a democratização do acesso à terra. (FELICIANO, 2006, p. 41).

Nesse cenário, restou aos movimentos sociais desenvolverem estratégias para avançar na luta pela terra e pela reforma agrária. As experiências com as ocupações de terra, acampamentos e marchas fortaleceram a ofensiva contra o latifúndio e contra o capital, resultando na conquista de muitos assentamentos rurais por meio da luta, do MST, da CPT, dos STRs, dentre outros, no estado de Goiás. No entanto, quanto mais os 
movimentos sociais se fortaleciam, mais os latifundiários intensificavam seus ataques e tentativas de criminalização das lideranças na perspectiva de impedir as ocupações de terra.

O gráfico 03 ilustra a quantidade de ocupações e de famílias envolvidas nessa estratégia.

Gráfico 03: Estado de Goiás - Ocupações realizadas pelos movimentos sociais de luta pela terra no período (1991-2018)

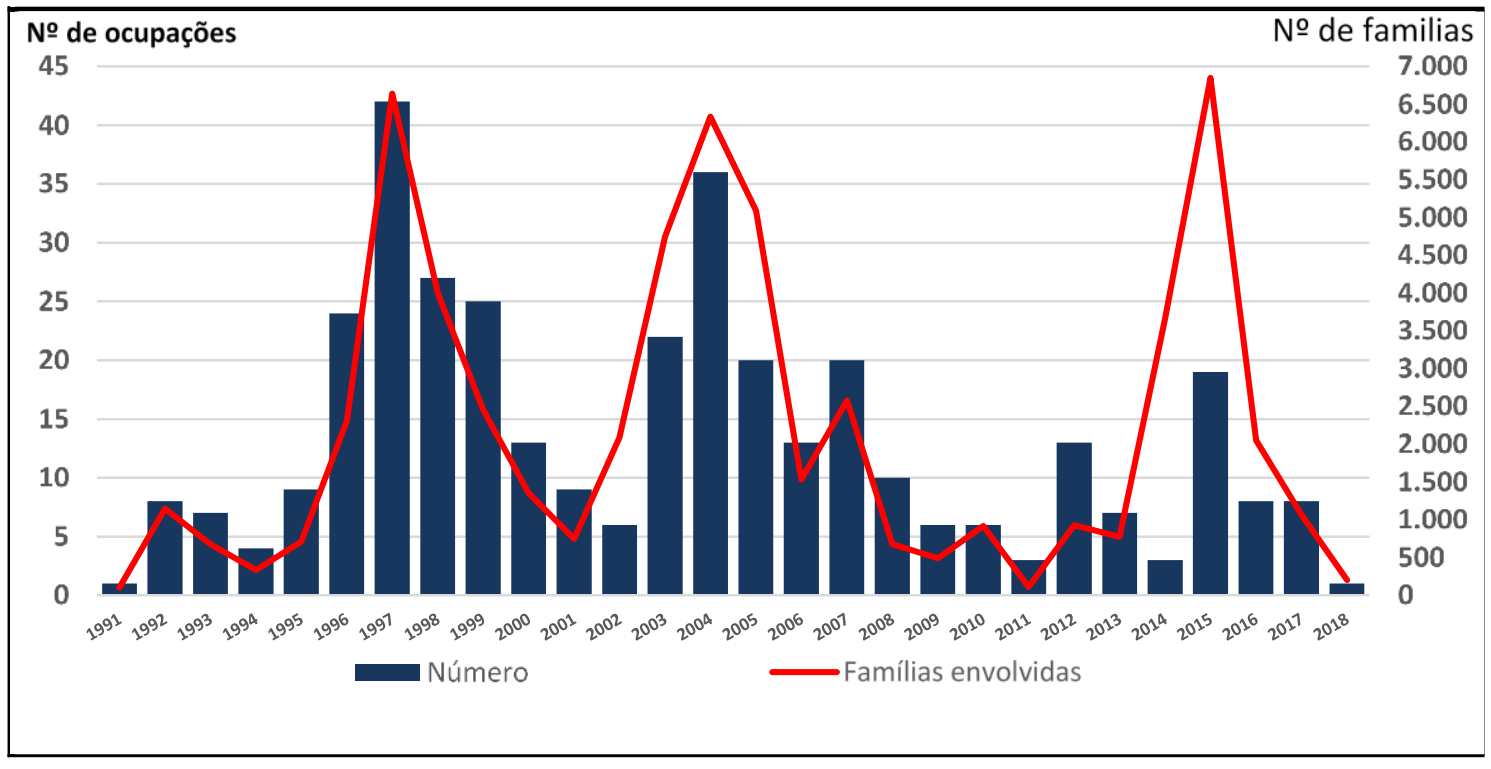

Fonte: CPT - Caderno de conflitos (1991-2018).

Elaboração: Manoel Calaça, 2020.

Podem ser destacados três diferentes períodos de concentração das ocupações. O primeiro deles ocorreu de 1996 a 2000, com destaque para o ano de 1997, quando se verificou um pico do número de famílias envolvidas em ocupações de terra. Esta data coincide com a realização da grande Marcha do MST para Brasília que reuniu mais de 100 mil pessoas em sua chegada na Capital Federal. A queda verificada desde então, tanto nas ocupações quanto no número de famílias envolvidas, acentuada a partir de 2000, pode ser pelo menos em parte explicada pela edição da Medida Provisória nº 21.183/2001, que em seu Art. $2^{\circ}$, transcrito abaixo, proibiu a desapropriação por interesse social de terras ocupadas por sem-terra.

[...] $§ 6^{\circ} \mathrm{O}$ imóvel rural de domínio público ou particular objeto de esbulho possessório ou invasão motivada por conflito agrário ou fundiário de caráter coletivo não será vistoriado, avaliado ou desapropriado nos dois anos 
seguintes à sua desocupação, ou no dobro desse prazo, em caso de reincidência; e deverá ser apurada a responsabilidade civil e administrativa de quem concorra com qualquer ato omissivo ou comissivo que propicie o descumprimento dessas vedações. $\S 7^{\circ}$ Será excluído do Programa de Reforma Agrária do Governo Federal quem, já estando beneficiado com lote em Projeto de Assentamento, ou sendo pretendente desse benefício na condição de inscrito em processo de cadastramento e seleção de candidatos ao acesso à terra, for efetivamente identificado como participante direto ou indireto em conflito fundiário que se caracterize por invasão ou esbulho de imóvel rural de domínio público ou privado em fase de processo administrativo de vistoria ou avaliação para fins de reforma agrária, ou que esteja sendo objeto de processo judicial de desapropriação em vias de imissão de posse ao ente expropriante; e bem assim quem for efetivamente identificado como participante de invasão de prédio público, de atos de ameaça, sequestro ou manutenção de servidores públicos e outros cidadãos em cárcere privado, ou de quaisquer outros atos de violência real ou pessoal praticados em tais situações. $\S 8^{\circ} \mathrm{A}$ entidade, a organização, a pessoa jurídica, o movimento ou a sociedade de fato que, de qualquer forma, direta ou indiretamente, auxiliar, colaborar, incentivar, incitar, induzir ou participar de invasão de imóveis rurais ou de bens públicos, ou em conflito agrário ou fundiário de caráter coletivo, não receberá, a qualquer título, recursos públicos. (BRASIL, 2001, n.p.).

Esse refluxo nas lutas somente foi revertido a partir de 2003, a partir da expectativa gerada pela eleição do Presidente Lula, historicamente comprometido com as causas sociais, incluindo a reforma agrária. Possivelmente, a esperança em torno de um governo popular, que finalmente colocasse a reforma agrária como uma de suas prioridades, produziu um novo pico de ocupações em 2004. Entretanto, diante de metas tímidas de desapropriações e assentamentos aos poucos foi se desfazendo as expectativas criadas.

Nos anos subsequentes, observou-se queda gradativa até 2011, possivelmente, devido ao aumento nas taxas de emprego e as políticas sociais que atenderam grande parte da população pobre e expropriada, com programas como Bolsa Família; Minha Casa Minha Vida; Luz para Todos; etc., e o pacto de classe que manteve Lula no poder até o fim dos seus dois mandatos. Esses mesmos fatores podem explicar a retomada lenta das ocupações de 2012 a 2018, sendo esse último período marcado pela crise econômica que perdura até hoje e pelo impeachment da Presidenta Dilma, que resultou também em grave crise política.

O processo de socialização da luta camponesa ocorre em frações de tempo e espaço desigual ao processo de despolitização do capital contra a luta camponesa. A velocidade do capital aliado à estrutura do Estado tenta despolitizar e desacreditar os movimentos sociais o quanto antes. Mas essa despolitização não tem uma unidade coesão. O movimento camponês sempre devagar, mas não divagando, vai demonstrando indicadores da possibilidade de se construir outro território. (FELICIANO (2006, p. 99). 
Cartograma 01: Estado de Goiás - Distribuição espacial dos assentamentos e das famílias assentadas, por município (1986-2015)

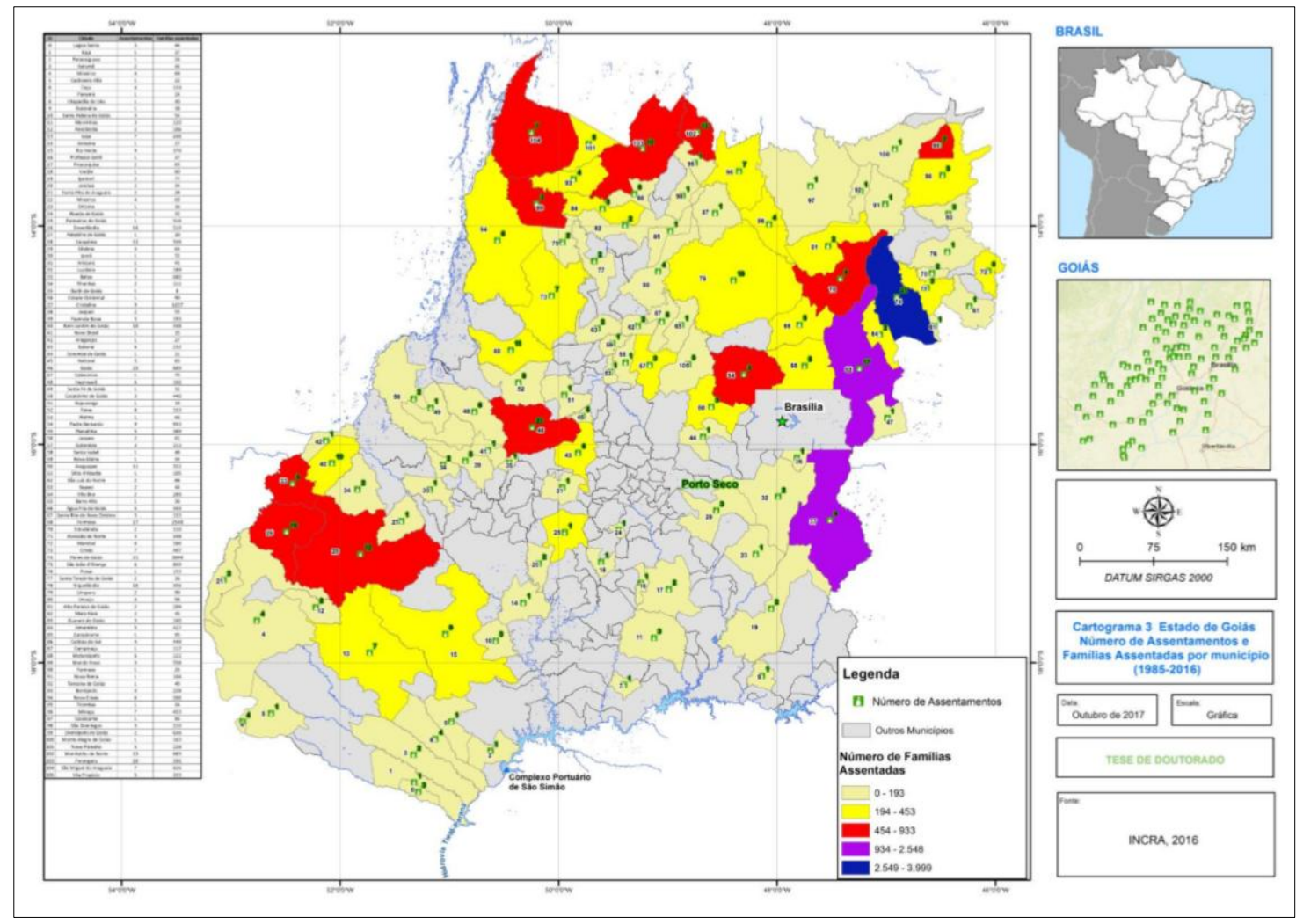

Fonte: INCRA - Elaborado por Silva, 2018, p. 156.

O Cartograma 01 apresenta a distribuição espacial dos assentamentos e das famílias assentadas, indicando forte concentração nas regiões Noroeste, Leste e Norte do estado de Goiás.

Vê-se, pois, que a fixação de assentamentos rurais nem sempre viabiliza condições favoráveis à produção. A maioria dos assentamentos rurais se encontram distantes dos principais centros urbanos do estado e do Distrito Federal. A reforma agrária é uma necessidade social, no entanto, definitivamente, não está na pauta política. As conquistas obtidas não são capazes de criar estímulos que resultem em novas conquistas. A luta não para na simples ocupação, uma vez que é necessário também lutar pela infraestrutura, financiamento e outras logísticas para viabilizar a produção e escoamento dos produtos cultivados.

Apesar disso, ainda que a passos lentos, como resultado da pressão popular vê-se a formação de um território camponês com a conquista de centenas de assentamentos rurais no estado de Goiás e nos demais estados da Região Centro-Oeste (Tabela 1 e 
Gráfico 3). A Tabela 1 contém os dados referentes aos assentamentos rurais na Região

Centro-Oeste no período de 1984 a 2017, segundo os dados oficiais do INCRA.

$\mathrm{O}$ estado do Mato Grosso tem os maiores valores referentes às variáveis consideradas, com 52,94\% dos assentamentos, mais de $82 \%$ do número de famílias assentadas e 75,42\% da área ocupada. O estado de Goiás tem 19,86\% dos assentamentos, $34,41 \%$ das famílias assentadas e 13,84\% da área ocupada, ocupando o segundo lugar considerando essas três variáveis.

Tabela 01: Região Centro-Oeste - Número de assentamentos, de famílias assentadas e áreas dos assentamentos rurais por UF (1984-2017)

\begin{tabular}{c|cc|cc|cc}
\hline \multirow{2}{*}{ UF } & \multicolumn{2}{|c|}{$\mathbf{N}^{\mathbf{0}}$ assentamentos } & \multicolumn{2}{c|}{$\mathbf{N}^{\mathbf{0}}$ de famílias } & \multicolumn{2}{c}{ Área (ha) ocupada } \\
\cline { 2 - 7 } & $\mathbf{N}^{\mathbf{0}}$ & $\mathbf{\%}$ & $\mathbf{N}^{\mathbf{0}}$ & $\mathbf{\%}$ & Área (ha) & \% \\
\hline GO & 436 & 19,86 & 436 & 34,41 & $1.104 .974,60$ & 13,84 \\
DF & 78 & 7,52 & 78 & 6,16 & $141.775,87$ & 1,78 \\
MT & 549 & 52,94 & 549 & 43,33 & $6.023 .370,76$ & 75,42 \\
MS & 204 & 19,67 & 204 & 16,10 & $716.212,19$ & 8,97 \\
\hline Total & 1.037 & 100 & 1.267 & 100 & $723.482 .491,42$ & 100 \\
\hline
\end{tabular}

Elaboração: Manoel Calaça, 2020.

O Gráfico 04 relaciona a fixação dos assentamentos rurais e o número de famílias assentadas entre 1984 e 2017 no estado de Goiás. Verifica-se claramente dois períodos de maior concentração na execução de projetos. O primeiro, de 1995 a 2001 e o segundo, de 2004 a 2010, com redução nos anos seguintes. O período de 1995 a 2001 apresenta duas características marcantes: a agricultura passou por forte crise em consequência da abertura econômica e comercial e da adoção das políticas neoliberais no Brasil, durante os governos de FHC. Essa crise implicou queda das taxas de lucro no setor e na desvalorização do preço das terras, gerando pouca atratividade ao negócio agrícola. A segunda característica é que foi um período de muita luta social, ocupações de terra e da grande Marcha do MST a Brasília.

O segundo período, de 2004 a 2010, durante os governos do Presidente Lula, além de muitas lutas sociais, foi marcado por um processo de recuperação econômica do País e por outro marco nas relações e negociações com o movimento social. Entretanto, nesse mesmo período, em função de um cenário externo favorável e de políticas internas de estímulo, ocorreu grande fortalecimento econômico e político da agricultura empresarial, 
agora denominada agronegócio. Sua reinserção comercial no mercado externo de commodities, sem regulação fundiária, resultou em grande valorização das terras, que se constituiu em um entrave à implantação de assentamentos dentro dos marcos atuais. Seguramente, os números do Governo Dilma foram bastante afetados por essa variável, além da diminuição das lutas já analisadas anteriormente.

Gráfico 04: Estado de Goiás - Número de famílias assentadas e áreas dos assentamentos rurais (1984-2017)



Fonte: INCRA, 2020.

Org.: Manoel Calaça, 2020.

Já os governos Temer e Bolsonaro se caracterizam: primeiro pela desestruturação da estrutura do Estado voltada para a reforma agrária, com a extinção do Ministério do Desenvolvimento Agrário (MDA) e o total descaso com o Instituto Nacional de Reforma Agrária (INCRA); e segundo, pela extinção de políticas públicas voltadas tanto para a fixação quanto para o desenvolvimento dos assentamentos. Nesse contexto, tem-se o aumento da violência no campo, que num primeiro momento desencoraja os movimentos na realização de ocupações e outras lutas. Porém, o problema continua sem solução e sabemos que todo conflito não resolvido tende a se ressurgir a qualquer momento e com maior força. 
Dentre as organizações e movimentos sociais que lutam pela terra e pela reforma agrária em Goiás, destacam-se o MST, a CPT, o Movimento Terra Livre, a FETAEG e a Federação dos Trabalhadores na Agricultura Familiar (FETRAF), dentre outros. Pode-se dizer que como organizações coletivas e de luta são resultado de um processo histórico de formação, recriação e resistência do campesinato goiano e ao mesmo tempo construtores de novas práticas sociais, políticas, econômicas e culturais nos territórios de vida.

\section{Considerações Finais}

Como se pode verificar, do ponto de vista de seu dinamismo econômico, o estado de Goiás tem uma história diretamente ligada ao extrativismo mineral e à exploração agropecuária. A lógica desses sistemas produtivos foi responsável por produzir estrutura fundiária altamente concentrada e um domínio político exercido por poucas famílias desses verdadeiros "senhores da terra", que, ao longo dos anos, mantiveram e reproduziram o sistema de dominação a ferro e fogo, com o uso da violência contra quem ousasse levantar a voz e questionar seu sistema de poder.

Dessa estrutura de poder e propriedade desigual, reproduziram-se crescentes desigualdades econômicas e sociais, tanto no campo quanto nas cidades. O surgimento de inúmeros movimentos sociais, desde as heroicas lutas dos camponeses de Trombas e Formoso e Orizona, foi a forma encontrada pela sociedade, particularmente, pelos trabalhadores do campo, de questionar e lutar contra o processo de exclusão social. Muitos foram os conflitos por terra, por trabalho e dignidade, marcados por derrotas e vitórias, mas sem nunca deixar de lutar, mesmo em tempos difíceis.

Assim, a luta pela terra no estado de Goiás se caracteriza como luta em defesa da vida e que antecede a luta pela reforma agrária, mas continua concomitante a ela. Porque ousar lutar pela terra aqui significa enfrentar uma estrutura fundiária atrasada, a violência dos "senhores da terra" que relutam em renunciar os privilégios mantidos e repassados a gerações, além do poder de um Estado arraigado nos interesses das elites dominantes. Mesmo após a conquista de seu "pedaço de chão" a luta pela vida permanece, porque lutar pela terra se converte na luta para sobreviver na terra. Principalmente, porque boa parte dos assentamentos conquistados foram feitos em lugares distantes, de difícil acesso, em terras com baixa fertilidade natural, com quase nenhuma infraestrutura e sem 
acompanhamento algum por parte do Estado. Realidade que não é muito diferente para boa parte dos camponeses, agricultores familiares, quilombolas, indígenas e demais trabalhadores que vivem da terra.

O campo é muito mais do que produção agropecuária; é um espaço dialético formado por diferentes sujeitos, onde as disputas territoriais e conflitos se sucedem, mas é espaço de produção de vida, de manifestações culturais, de esperança, de ação coletiva, de afirmação e de construção de direitos. O campo é espaço de pessoas que aprenderam com história que, para quem vive do trabalho, a conquista só é possível com muita perseverança, organização e luta.

O velho latifúndio se apresenta hoje com nova roupagem, travestido de "moderno" - o agronegócio - mas continua sendo uma grande ameaça para os territórios camponeses,

quilombolas e indígenas. É notório que a expansão da fronteira agrícola, por meio da monocultura de soja, milho, cana-de-açúcar e pastagens, tem gerado desarticulação dos territórios da produção camponesa e se tornou uma das principais causas da violência no campo, que tem aumentado nas últimas décadas pela apropriação das áreas antes ocupadas com plantio de alimentos.

A criação de assentamentos rurais e a conquista de políticas públicas a partir das lutas e proposições dos movimentos sociais representaram significativos avanços, mas continuam sendo conquistas pontuais que não se pode confundir com reforma agrária.

Faz-se necessário o estímulo ao desenvolvimento de novas práticas produtivas que possam estabelecer outra relação com a terra e com os recursos naturais. A agroecologia, por exemplo, se apresenta, hoje, como uma dessas práticas, que, além de oferecer alimentos saudáveis e perspectiva de inclusão social, contribui para a preservação e recuperação do ambiente natural. Desse modo, vai se gestando nos territórios de vida elementos consistentes para um projeto contra hegemonia latifundiária na agricultura.

\section{REFERÊNCIAS}

BARBOSA, Altair Sales, TEIXEIRA NETO, Antônio e GOMES, Horieste. Geografia: Goiás-Tocantins. Edição Revisada e Ampliada. Goiânia, Ed. da UFG: 2005. 270p. il. BORGES, B. G. Goiás nos quadros da economia nacional: 1930-1960. Goiânia: Ed. da UFG, 2000. 142p. 
BRASIL. Medida Provisória nº 2.183, 24 de agosto de 2001. Brasília: Poder Executivo, 2001. n. p.

. Constituição da República Federativa do Brasil. Brasília: Congresso

Nacional, 1988. 130p.

BRUNO, Regina. União Democrática Ruralista (UDR). Verbete. Centro de Pesquisa e Documentação de História Contemporânea do Brasil (CPDOC). Rio de Janeiro, Fundação Getúlio Vargas, [1990?]. Disponível em: <http://www.fgv.br/cpdoc/acervo/dicionarios/verbetetematico/uniao-democratica-ruralista-udr $>$

CARNEIRO, Maria Esperança Fernandes. A revolta camponesa de Formoso e Trombas. 2ed. - São Paulo: Anita Garibaldi coedição com fundação Mauricio Grabois, 2014. 200p.

CONTAG-MG. Confederação Nacional dos Trabalhadores na Agricultura. Belo Horizonte: CONTAG, Informativo Terra $\mathrm{n}^{\circ}$ 2, maio de 1985.

FELICIANO, Carlos Alberto. Movimento camponês rebelde: reforma agrária no Brasil. São Paulo: Contexto, 2006. 205p.

INOCÊNCIO, Maria Erlan; CALAÇA, Manoel. Estado e Território no Brasil: reflexões a partir da agricultura no Cerrado. Revista IDeAS, v. 4, n. 2, p. 271-306.

KAUTSKY, K. A Questão Agrária. São Paulo, Nova Cultural - Os Economistas, 1986.

MAIA, Cláudio Lopes. Os donos da terra: a disputa pela propriedade e pelo destino da fronteira - a luta dos posseiros e, Trombas e Formoso 1950/1960. 274fl.Tese (Doutorado em História das Sociedades Agrárias) Instituto de Ciências Humanas e Letras. UFG/Goiânia. Goiânia, 2008. 274p.

MATOS, Helaine Saraiva, CUNHA, Gabriela Bento, ALENCAR, Francisco Amaro Gomes de. Panorama dos conflitos e da violência no espaço agrário brasileiro de 1985-2014. In. Conflitos no campo no Brasil 2014. Goiânia: CPT Nacional, 2014. 216p.

MEDEIROS, Arthur S. de. Antecedentes históricos da luta pela terra no Brasil e o surgimento do MST. nd. Disponível em:

<http://www.publicadireito.com.br/artigos/?cod=52d5d0f100d9de6a> Acesso em: 15 jan. 2020.

MENDONÇA. Marcelo Rodrigues. A urdidura do capital e do trabalho no cerrado do sudoeste goiano. 2004. $430 \mathrm{f}$. Tese (Doutorado em Geografia) Universidade Estadual Paulista, Presidente Prudente, 2004. 457p.

MORISSAWA, Mitsue. A história da luta pela terra e o MST. São Paulo: Expressão Popular, 2001. 256p. il. 
PALACÍN, Luiz e MORAES, Maria Augusta de Sant'Anna. História de Goiás. 7 ed.

Goiânia: ed. da UCG. Ed. Vieira, 2008. 184p.

PESSOA, Jadir Moraes de. A revanche camponesa. - Goiânia: Ed. da UFG, 1999. $351 \mathrm{p}$.

SANTOS, Milton; SILVEIRA M. L. O Brasil: território e sociedade no início do século XXI. Rio de Janeiro/RJ: Record, 2001. 351p.

SILVA, Edson Batista da. Tese. Cercados e a Contrapelo: As Expulsões e as Reações Camponesas à Acumulação Primitiva Permanente em Goiás (1970-2015). 525fl. Tese (Doutorado em Geografia). Instituto de Estudos Socioambientais, UFG/Goiânia, 2018.

Recebido em 24/03/2020.

Aceito para publicação em 21/05/2020. 